\title{
Current State of Musculoskeletal Ultrasound Training and Implementation among Rheumatologists in Arab Countries
}

\author{
Lamyae Bouhouche ${ }^{1 *}$, Hajar Lachhab Tazi ${ }^{1}$, Samira Rostom $^{1}$, Bouchra Amine ${ }^{1}$ and Rachid Bahiri ${ }^{1}$ \\ Mohammed Vth University, Ibn Sina universitary hospitals, El Ayachi hospital, Department of Rheumatology Rabat- \\ Salé, MOROCCO
}

Received: August 30, 2017; Accepted: September 26, 2017; Published: October 24, 2017

*Corresponding author: Lamyae Bouhouche, Mohammed Vth University, Ibn Sina universitary hospitals, El Ayachi hospital, Department of Rheumatology Rabat-Salé, MOROCCO, E-mail: lamyaebouhouche@hotmail.com

\begin{abstract}
Objective: To document the current state of Musculo Skeletal US (MSUS) implementation and training among Arab rheumatologists.

Methods: A questionnaire in English divided into 9 items and 4 domains (sociodemographic characteristics, training in MSUS, MSUS in clinical practice and access to equipment) was distributed to Arab rheumatologists who were present at the Panarab Congress of Rheumatology "ARLAR 2016", which tookplace from 24 to 26 March 2016 in Morocco.

Results: A total of 75 among 700 participants (11\%) have answered the questionnaire. Most of respondents have less than 50 years $(79.6 \%), 58 \%$ were female. MSUS was practiced daily by 37 $(49.3 \%)$ respondents. Severalrespondents have formal university training $(35.6 \%)$, few ones have informal training provided by rheumatologists $(10.2 \%), 53.2 \%$ attended MSUS courses or Workshops and $75 \%$ have access to MSUS. They use MSUS in the following indications : rheumatoid arthritis $(85.5 \%)$, shoulder pain (76.3\%), ankle pain(50\%), peripheral spondyloarthritis (51.3\%) and for guidance of interventional procedures in $47.2 \%$.

Conclusion: Our results suggest that most of Arab rheumatologists have accessto MSUS machine and have been trained by attending MSUS courses or Workshops, but only a half uses MSUS in their daily practice.
\end{abstract}

Keywords: Musculoskeletal ultrasound; Implementation; Arab countries;

\section{Abbreviations}

MSUS : Musculoskeletal ultrasound

RA : Rheumatoid Arthritis

OMERACT: Outcome Measures in Rheumatoid Arthritis Clinical Trial

JIA : Juvenile Idiopathic Arthritis

EULAR : the European League Against Rheumatism

UAE : United Arab Emirates
KSA : Kingdom of Saudi Arabia

ARLAR: Arab League Against Rheumatism

TTT : Teaching The Teachers

ECRIN: Ultrasound Rheumatology on Internet

\section{Introduction}

Musculoskeletal Ultrasound (MSUS) is a safe and a non invasive technique that had a good satisfaction and acceptability from patients [1]. It has been increasingly incorporated into rheumatologists's practice during the last decade.In fact, it has been established to evaluate joints lesions in patients with rheumatic diseases, to assess individual's response to treatment and to guide interventional procedures [2,3]. MSUS may help the physician to diagnose early rheumatoid arthritis (RA) and provide many advantages over the other imaging tools $[4,5]$. In addition to being non-irradiant, ultrasound is a less costly technology providing comparative and dynamic exam [6]. Conversely, the maindisadvantages of MSUS are the long training duration before acquiring sufficient competency and the operator depending characteristic of this technique [2].

The pathological definition of synovial hypertrophy, enthesopathy, tenosynovitis and bone erosion was reported by the Outcome Measures in Rheumatoid Arthritis (RA) Clinical Trial (OMERACT) ultrasound working group [7]. The same group had published recently the definition of the minimal disease activity in RA by MSUS and the scoring system for synovitis in Juvenile Idiopathic Arthritis (JIA) [8]. Some organizations have published recommendations and guidelines for the standard format and elements of MSUS report, in order to standardize the MSUS examination and interpretation, [9-11].

European countries were the first to incorporate MSUS into rheumatologists's practice and have developed training programs and curriculum under theumbrella of both the European League Against Rheumatism (EULAR) and the Outcome Measurement in Rheumatology Clinical Trials (OMERACT) group [12]. 
In recent years, Arab countries have performed great progress at the use of MSUS by rheumatologists. Many Arab Colleges of Rheumatology, especially in Morocco, Algeria, United Arab Emirates (UAE), Kingdom of Saudi Arabia(KSA) and Egypt have developed training programs for MSUS and organized national symposiums and courses to improve the percentage of rheumatologists performing this technique. This study aimed to evaluate how Arab rheumatologists currently use MSUS and to analysis their training modalities.

\section{Methods}

An English-language questionnaire with multiple-choice questions was designed in order to analyze the current state of training and practice of MSUS by Arab rheumatologists, following some European, American and Asian studies [13-19]. It was distributed to Arab rheumatologists who were present at the Panarab Congress of Rheumatology "ARLAR 2016", which took place from 24 to 26 March 2016 in Marrakech in Morocco. The questionnaire could be completed in roughly 3 minutes. It consists of 9 items and 4 domains: socio-demographic characteristics, training in MSUS, MSUS in clinical practice and access toequipment. Responses were analyzed blindly.

A descriptive analysis was performed using the software program SPSS (version21.0) and Microsoft Excel.

\section{Results}

A total of 76 rheumatologists have answered the questionnaire between 700 participants in the Congress (11\%). Demographic characteristics of the respondents and clinical practice of MSUS are summarized in Tables 1 and 2, respectively.

\begin{tabular}{|c|c|}
\hline Parametrs & $N=76$ \\
\hline Daily practice of MSUS & $37(49.3 \%)$ \\
\hline \multicolumn{2}{|l|}{ Duration of MSUS practice (years) } \\
\hline - $\quad<5$ & $24(64.9 \%)$ \\
\hline - $5-10$ & $11(29.7 \%)$ \\
\hline - $\quad>10$ & $2(5.4 \%)$ \\
\hline Access to the equipment & $58(77.3 \%)$ \\
\hline - Personal & $7(12.3 \%)$ \\
\hline - $\quad$ Shared & $50(87.7 \%)$ \\
\hline US-guided interventions & $34(47.2 \%)$ \\
\hline Rheumatologists trained in MSUS & $57(76 \%)$ \\
\hline - $\quad$ Formal university training & $21(35.6 \%)$ \\
\hline - Informal training from rheumatologists & $6(10.2 \%)$ \\
\hline $\begin{array}{l}\text { - Attendance at an MSUS courses or } \\
\text { Workshops }\end{array}$ & $32(53.2 \%)$ \\
\hline
\end{tabular}

\begin{tabular}{|l|l|}
\hline \multicolumn{2}{|l|}{ Table 1: Demographic characteristics of the 76 respondents } \\
\hline Parametrs & $\mathbf{N}=76$ \\
\hline Age (years) & $4(5.3 \%)$ \\
\hline$<30$ & $25(33.3 \%)$ \\
\hline $30-40$ & $28(37.3 \%)$ \\
\hline $40-50$ & $18(24 \%)$ \\
\hline$>50$ & $44(58.7 \%)$ \\
\hline Female & \\
\hline Clinicalexperience (years) & $26(35.6 \%)$ \\
\hline$\leq 10$ & $29(39.7 \%)$ \\
\hline $20-$ Oct & $14(19.2 \%)$ \\
\hline $20-30$ & $4(5.5 \%)$ \\
\hline$>=30$ & \\
\hline Sector of activity & $13(18.6 \%)$ \\
\hline Private practice & $26(37.1 \%)$ \\
\hline Regionalhospital & $31(44.3 \%)$ \\
\hline Universityhospital & \\
\hline Nationality & $18(23.7 \%)$ \\
\hline Morocco & $15(19.7 \%)$ \\
\hline Algeria & $9(11.8 \%)$ \\
\hline Tunisia & $8(10.5 \%)$ \\
\hline Egypt & $18(23.7 \%)$ \\
\hline Ksa & $5(6.6 \%)$ \\
\hline Iraq & $1(1.3 \%)$ \\
\hline Oman & $2(2.6 \%)$ \\
\hline Kuwait & \\
\hline & \\
\hline
\end{tabular}

\section{Demographics}

Most of respondents (76\%) were aged less than 50 years old. Forty four (58.7\%)were female. They worked in a hospital/ tertiary care centers $(44.3 \%)$, at regional hospitals (37.1\%), or in a private practice $(18.6 \%)$. Twenty six participants(35.6\%) have less than ten years experience.

\section{Education and training}

Fifty seven $(76 \%)$ participants had some kind of training in MSUS. The most common forms of training under taken were as follows: Formal academic university training (35.6\%), informal training from rheumatologists $(10.2 \%)$ and most of them have attended MSUS courses or Workshops (54.2\%).

\section{Current practice}

Fifty eight $(77.3 \%)$ respondents have access to MSUS machines. MSUS was used for less than five years duration by $64.9 \%$ of respondents and more than ten years by only $5.4 \%$. MSUS was practiced daily by $37(49.3 \%)$ respondents, but just seven $(12.3 \%)$ have their own equipment. This technique was considered tobe most useful in the following indications: 


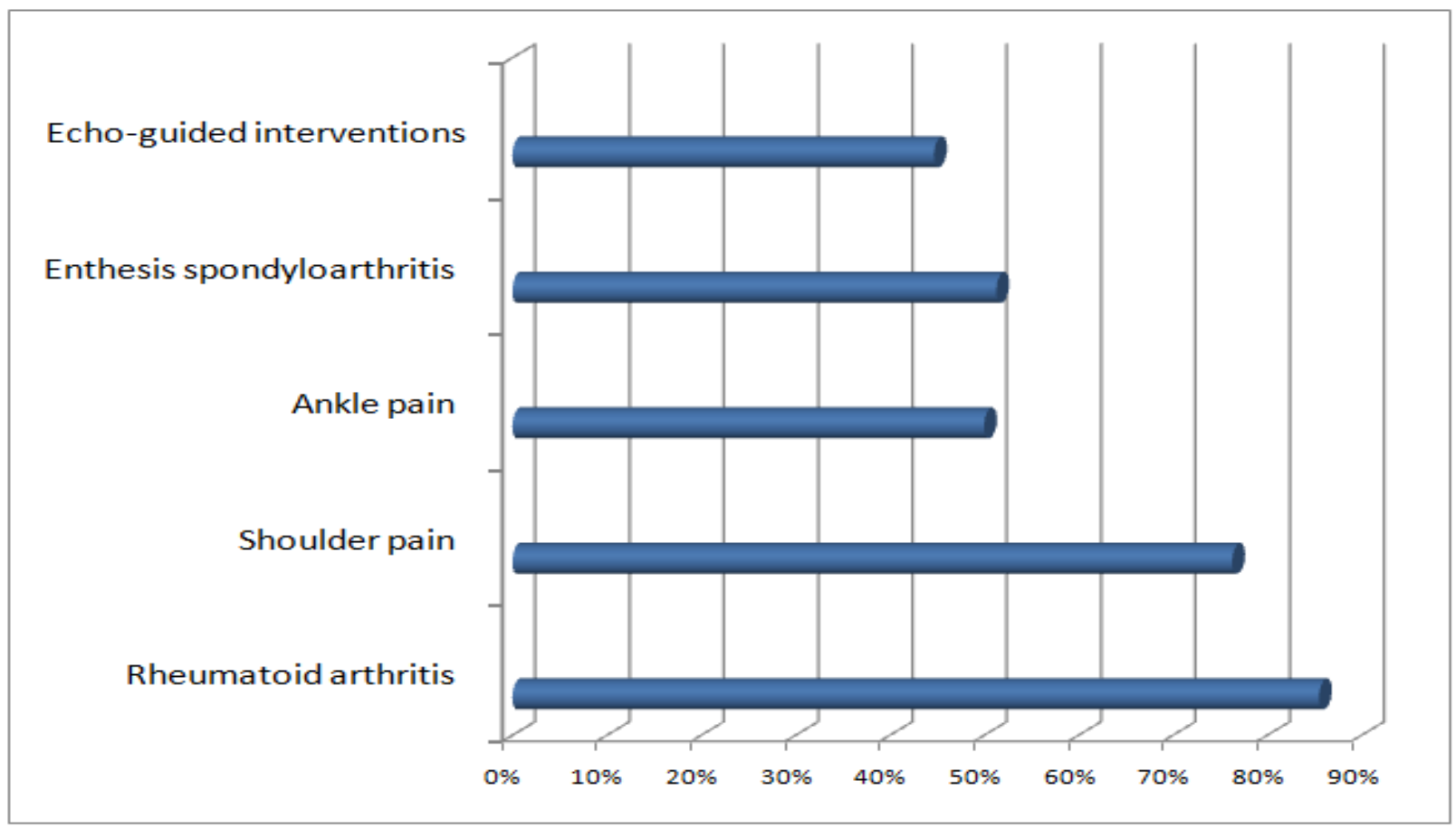

Figure 1: Indications for MSUS according to Arab rheumatologists.

rheumatoid arthritis (85.5\%),shoulder pain (76.3\%), ankle pain (50\%), peripheral spondyloarthritis (51.3\%)and for guidance of interventional procedures in $47.2 \%$ (Figure 1).

\section{Discussion}

Many papers have been published in the last decade showing the great interest of rheumatologists in MSUS in their daily practice and in research settings. In addition to its advantages compared to other imaging tools, MSUS has provedits usefulness to help clinicians to specify diagnosis, prognosis and to monitorthe disease activity, indication and evaluation of therapeutic effects [5,20-22].

Several surveys across many countries have been published to study the implementation, training and teaching of MSUS [12,15,16,23-25]. European rheumatologists adopted MSUS into their practices earlier than their colleagues from other continents $[21,10]$. The current survey represents the first study across Arab countries assessing the implementation of MSUS in routine rheumatology practice. Our results suggest that the majority of Arab rheumatologists are interested and learning MSUS, but only a half is daily using this technology. The main indications were as follows: rheumatoid arthritis,shoulder pain, peripheral spondyloarthritis, ankle pain and guidance of interventional procedures. MSUS was used for procedures guidance by $47.2 \%$ of respondents, more frequently than European and Japanese rheumatologists $[12,16,26]$.

Many surveys found that the lack of training was the major concern hampering the spread of MSUS among rheumatologists $[15,16,27]$. In fact, Maasa et al. found that the development of training courses and informal training have doubled the number of MSUS users in Japan over 3 years [28]. At present, no standard educational training program in MSUS exists, and there is no consensus for evaluating competency of rheumatologists using MSUS. In 2001, the EULAR working group for MSUS had developed guidelines to standardize MSUS imaging methods [29]. The same group had developed recently a manual with guidelines representing an educational support to organize the MSUS Teaching The Teachers (TTT) courses in order to improve and homogenize the training [30]. In our study, most of rheumatologists have been trained by attending MSUS courses or Workshops; the second way was by formal academic university education. For example, in Morocco, there is a formal academic curriculum that consisted of theoretical and practical courses over one year in three sessions, organized by the University of Medicine of Rabat and taught by Moroccan seniors of rheumatology who are expert in MSUS. At the end of training, the competency assessment is based on theoretical and practical examination and a specific certified university diploma of MSUS in rheumatology is awarded to the participants. In Algeria, the training in MSUS is modeled on the French diploma of rheumatologic ultrasound (ECRIN) and taught by the same training team. In Middle East, especially UAE, KSA and Egypt, they have developed annual theoretical and practical courses taught by international or local experts in MSUS.

The limitation of our study was the low response rate compared to previous surveys $[15,17,25,31]$. So, our results may reflect only a part of Arab rheumatologists practice. The second possible bias is that in such direct surveys conducted during conferences, doctors that accept to participate may be essentially the ones who were trained and interested in MSUS. 


\section{Conclusion}

The MSUS is an important tool to complete physical examination and to improve patient care. Implementation of MSUS into rheumatologic practice must to be planned. Continuing education is important to be up to date with the development of scientific data and technology. This is the first study to evaluate and analyze MSUS use among Arab rheumatologists. It seems that most of themare interested and practice this technique and are attending MSUS courses and/or Workshops. The lack of standard educational training program and assessment of competency in MSUS, in addition to the lack of expert comparedto the great need and demand for education on MSUS still seem to be the main obstacles for the diffusion of MSUS worldwide.

\section{Declarations}

Ethics approval and consent to participate: All procedures performed in this study were in accordance with the ethical standards of the national research committee and with the 1964 Helsinki declaration. Informed consent was obtained from all individual participants included in the study.

Authors' Contributions: We declare that we participated in the study as following: RB, SR and BA conceived the study and supervised its design and execution. LB and HTL participated in the data collection and statistical analysis. LB and RB drafted the manuscript. All authors read and approved the final manuscript.

\section{Acknowledgements}

We would like to thank all of rheumatologists who responded the survey and who participated in the data collection.

\section{References}

1. Acebes C, Harvie JP, Wilson A, Duthie J, Bowen F, Steven M. Clinical usefulness and patient satisfaction with a musculoskeletal ultrasound clinic: results of a 6-month pilot service in a Rheumatology Unit. Rheumatol Int. 2016;36(12):1677-1681.

2. Iagnocco A, Naredo E, Bijlsma JWJ. Becoming a musculoskeletalultrasonographer. Best Practice \& Research Clinical Rheumatology. 2013;27(2):271-281.

3. Ali Ou Alla S, Bahiri R, Amine H, El Alaoui H, Rkain H, Aktaou S, et al. Ultrasound features of shoulder involvement in patients with ankylosing spondylitis: a case-control study. BMC Musculoskelet Disord. 2013;14:272. doi: 10.1186/1471-2474-14-272

4. Hmamouchi I, Bahiri R, Srifi N, Aktaou S, Abouqal R, Hajjaj-Hassouni N. A comparison of ultrasound and clinical examination in the detection offlexor tenosynovitis in early arthritis. BMC Musculoskelet Disord. 2011;12:91. doi: 10.1186/1471-2474-12-91

5. Lage-Hansen PR, Lindegaard H, Chrysidis S, Terslev L. The role ofultrasound in diagnosing rheumatoid arthritis, what do we know? An updatedreview. Rheumatol Int. 2017;37(2):179-187. doi: 10.1007/ s00296-016-3587-z

6. Sudoł-Szopińska I, Jans L, Teh J. Rheumatoid arthritis: what do MRIand ultrasound show. J Ultrason. 2017;17(68):5-16. doi: 10.15557/ JoU.2017.0001

7. Wakefield R, Balint PV, Szkudlarek M, Filippucci E, Backhaus M, D'Agostino MA, et al. Musculoskeleta lultrasound including definitions for ultrasonographic pathology. J Rheumatol. 2015;32(12):2485-2487
8. Terslev L, Iagnocco A, Bruyn GAW, Naredo E, Vojinovic J, Collado P, et al. The OMERACT UltrasoundGroup: A Report from the OMERACT 2016 Meeting and Perspectives. JRheumatol. 2017; 44(10):2. doi: 10.3899/ jrheum.161240

9. Iagnocco A, Porta F, Cuomo G, DelleSedie A, Filippucci E, Grassi W, et al. The Italian MSUSStudy Group recommendations for the format and content of the report and documentation in musculoskeletal ultrasonography in rheumatology.Rheumatology. 2014; 53(2):367373. doi: $10.1093 /$ rheumatology/ket356

10. Cannella AC, Kissin EY, Torralba KD, Higgs JB, Kaeley GS. Evolution of musculoskeletal ultrasound in the United States: implementation and practice in rheumatology. Arthritis Care Res (Hoboken). 2014; 66(1):7-13. doi: 10.1002/acr.22183

11. American Institute of Ultrasound in Medicine (AIUM). AIUMPractice Guideline for Documentation of an Ultrasound Examination. J Ultrasound Med. 2014;33:2219-2224. doi: 10.7863/ultra.33.12.2219

12. Naredo E, D'Agostino MA, Conaghan PG, Backhaus M, Balint P, Bruyn GA, et al. Current state of musculoskeletal ultrasound training and implementation in Europe: results of asurvey of experts and scientific societies. rheumatology. 2010; 49(12):2438-2443. doi: 10.1093/ rheumatology/keq243

13. Mandl P, Naredo E, Conaghan PG, Backhaus M, Wakefield RJ, Bachta A, et al. Practice of ultrasound-guidedarthrocentesis and joint injection, including training and implementation, inEurope: results of a survey of experts and scientific societies. Rheumatology. 2012 ;51(1):184190. doi: $10.1093 /$ rheumatology/ker331

14. Tămaş MM, Fodor D, Rednic N Rednic S. Musculoskeletal ultrasonography inRomania-Results from a specific questionnaire. Med Ultrason. 2011; 13(1):10-14.

15. Samuels J, Abramson SB, Kaeley GS. The Use of MusculoskeletalUltrasound by Rheumatologists in the United States. Bull NYU HospJtDis. 2010; 68(4):292-298.

16. Takase K. Ohno S. Ideguchi H, Takeno M, Shirai A, Ishigatsubo Y,et al.Use of musculoskeletal ultrasound in Japan: a survey of practicing rheumatologists. Mod Rheumatol. 2010; 20(4):376-380. doi: 10.1007/s10165-010-0293-7

17.Wong SPY, Kwan CH. Current state of the use of musculoskeletalultrasound (MSUS) and view on the future development of MSUS training andservices in Hong Kong: Results of a survey among the members of the HongKong Society of Rheumatology. Hong Kong Bulletin on Rheumatic Diseases. 2016;16(1):1-5.

18. Janta I, Terslev L, Ammitzbøll-Danielsen M, Kosevoi-Tichie A, BernerHammerH, Naredo E,et al. EFSUMB COMPASS for Rheumatologists dissemination and implementation-an international survey. Med Ultrason . 2016;18(1):42-46. doi: 10.11152/ mu.2013.2066.181.iuj

19. Mandl P, Baranauskaite A, Damjanov N, Maja Hojnik, Reka Kurucz, Orsolya Nagy, et al. Musculoskeletal ultrasonography in routine rheumatology practice: data from Central and EasternEuropean countries. Rheumatol Intn. 2016;36:845-854. doi: 10.1007/s00296016-3442-2

20. Díaz- Torné C, Moragues C, Toniolo E, Geli C, Castellví I, Moya P,et al. Impact of ultrasonography on treatment decision in rheumatoid arthritis: the IMPULSARstudy. RheumatolInt.2017; 37(6):891-896. doi: 10.1007/s00296-017-3689-2 
21. Sakellariou G, Conaghan PG, Zhang W, Bijlsma JWJ4, Boyesen P5, D'Agostino MA6,7, et al. EULAR recommendations for the use of imaging in the clinical management ofperipheral joint osteoarthritis. Ann Rheum Dis. 2017;76(9):1484-1494. doi:10.1136/ annrheumdis-2016-210815

22.Płaza M, Nowakowska-Płaza, PracońG, Sudoł-Szopińska I. Roleof ultrasonography in the diagnosis of rheumatic diseases in light ofACR/EULAR guidelines. J Ultrason. 2016;16(64):55-64. doi: $10.15557 /$ JoU.2016.0006

23. Hernández-Díaz C, Ventura-Ríos L, Gutiérrez M, Roth J.Ultrasonography in pediatric rheumatology in Latin America. Expanding the frontiers. Clin Rheumatol. 2016;35(4):1077-1080. doi: 10.1007/s10067-0163217-x

24. Taggart AJ, Wright SA, Ball E, Kane D, Wright G. The Belfastmusculoskeletal ultrasound course..Rheumatology (Oxford). 2009;48(9):1073-1076. doi: 10.1093/rheumatology/kep075

25. Duftner C, Schu"ller-Weidekamm C, Mandl P, Nothnagl T, Schirmer M, Kainberger F, et al. Clinical implementation of musculoskeletal ultrasound in rheumatology in Austria. Rheumatol Int. 2014;34(8):1111-1115. doi: 10.1007/s00296-013-2863-4
26. Miguela E, Andreub JL, Naredoc E, Möllerd I. Situación de laecografía en la reumatologíaespaňola 2012. Reumatol Clin $2012 ; 8: 310-314$.

27. Platt P, Raftery G, Kane D. Attitudes of United Kingdomrheumatologists to musculoskeletal ultrasound practice and training JoannaCunnington. Ann Rheum Dis.2007; 66(10):1381-1383. doi: 10.1136/ard.2006.065466

28. Backhaus M, Bumester GR, Gerber T, Grassi W, Machold KP, Swen WA, et al. Guidelines formusculoskeletal ultrasound in rheumatology. Ann Rheum Dis .2001;60(7):641-9.

29. Hama M,Takase K, Ihata Ai, Ohno S, Ueda A, Takeno M,et al. Challenges to expanding theclinical application of musculoskeletal ultrasonography (MSUS) among rheumatologists: from a second survey in Japan. Mod Rheumatol.2012; 22(2):202-8.

30. Iagnocco A, Terslev L, Backhaus M, Balint P, Bruyn GA, Damjanov N, et al. Educational recommendationsfor the conduct, content and format of EULAR musculoskeletal ultrasoundTeaching the Teachers Courses. RMD Open. 2015;1(1):e000139. doi: 10.1136/rmdopen-2015-000139

31. Kellerman SE, Herold J. Physician response to surveys. Am J Prev Med. 2001;20(1):61-67. 